\title{
Redes de Pesquisa em Educação e Colaboração Científica
}

\author{
Altina Abadia da Silva ${ }^{1}$ \\ Cláudia Tavares do Amaral² \\ Luciana Barros de Almeida ${ }^{3}$
}

\section{RESUMO}

Nosso objetivo é compreender as formas de atuação das redes de pesquisa em educação e colaboração científica e a cooperação com a universidade brasileira. Fizemos uma pesquisa bibliográfica para reunir dados na investigação proposta tendo como base de dados: Rede Universitas, RedeEstrado, Rede Aste, RedeCentro, RIEOnLIFE. Como resultados, identificamos que a criação de redes acontece dentro de critérios científicos e/ou acadêmicos tendo, em alguns casos, critérios econômicos, formativos para ampliar possibilidades de publicações, isso responde as questões constituintes de algumas redes aqui analisadas, mostra a crise financeira da universidade brasileira enquanto entidade de pesquisa, e a necessidade de alinhamento com fontes externas de fomento e ao cumprimento da métrica das agências avaliadoras. As considerações finais, do ponto de vista crítico analítico, evidenciam processos em confronto e, ao mesmo tempo, complementares. Estamos convictas da importância do trabalho em rede, pois a vinculação possibilita ao pesquisador a aquisição de conhecimentos novos, além de observar um esforço mútuo nas dinâmicas empreendidas em prol da consolidação de redes de pesquisa, e na manutenção dos grupos de pesquisa.

Palavras-Chave: Redes de pesquisa. Critérios formativos. Universidade brasileira. Colaboração científica. Financiamento de pesquisa.

\footnotetext{
${ }^{1}$ Doutora em Educação. Universidade Federal de Catalão, Catalão, Goiás, Brasil. Orcid: https://orcid.org/0000-00027496-5556. E-mail: tinaufg8@gmail.com.

${ }^{2}$ Doutora em Educação. Universidade Federal de Catalão, Catalão, Goiás, Brasil. Orcid: https://orcid.org/0000-00032859-9353. E-mail: claudiatamaral@ gmail.com.

${ }^{3}$ Mestranda em Educação. Universidade Federal de Catalão, Catalão, Goiás, Brasil. Orcid: https://orcid.org/00000001-7099-4686. E-mail: $\underline{\text { lucianabarrosdealmeida@gmail.com. }}$
} 
Scientific Collaboration and Education Research Networks

\begin{abstract}
We aim to understand how research networks work in education and scientific collaboration and the cooperation with Brazilian universities. We did bibliographical research to gather data in the proposed investigation having a database: Rede Universitas, RedeEstrado, Rede Aste, RedeCentro, RIEOnLIFE. As a result, we identified that the creation of networks takes place within scientific and/or academic criteria having, in some cases, economic and training criteria to expand the possibilities of publications, this answers the constituent questions of some networks analyzed here, shows the financial crisis of Brazilian universities as a research entity, and the need for alignment with external funding sources and compliance with the metrics of the rating agencies. The final considerations, from a critical and analytical point of view, show processes that are confronting and, at the same time, complementary. We are convinced of the importance of working in a network, as the connection allows the researcher to acquire knowledge, in addition to observing a mutual effort in the dynamics engaged towards the consolidation of research networks, and in the maintenance of research groups.
\end{abstract}

KEYWORDS: Research networks. Teacher training. Teaching Work. Scientific Collaboration. Research financing.

\title{
Redes de investigación en educación y colaboración científica
}

\section{RESUMEN}

Nuestro objetivo es comprender las formas de actuación de las redes de investigación en educación y colaboración científica y cooperación con la universidad brasileña. Hicimos una pesquisa bibliográfica para recopilar datos en la investigación propuesta teniendo como base de datos: Rede Universitas, RedeEstrado, Rede Aste, RedeCentro, RIEOnLIFE. Como resultados, identificamos que la creación de redes ocurre dentro de criterios científicos y / o académicos teniendo, en algunos casos, criterios económicos y formativos para ampliar las posibilidades de publicaciones, esto responde a las preguntas constitutivas de algunas redes aquí analizadas, muestra la crisis financiera de la universidad brasileña como entidad de investigación, y la necesidad de alineación con fuentes de estímulos externos y 
cumplimiento de las métricas de las agencias calificadoras. Las consideraciones finales, desde un punto de vista analítico crítico, muestran procesos enfrentados y, al mismo tiempo, complementarios. Estamos convencidos de la importancia de trabajar en red, ya que el vínculo permite al investigador adquirir nuevos conocimientos, además de observar un esfuerzo mutuo en las dinámicas emprendidas en relación a la consolidación de redes de investigación, y el mantenimiento de grupos de investigación.

PALABRAS CLAVE: Redes de investigación. Formación de profesores. Trabajo docente. Colaboración científica. Fondos de investigación.

$$
* * *
$$

\section{Introdução}

Em diversas circunstâncias, por um lado é recorrente o desafio de empreender uma pesquisa, devido ao caráter, muitas vezes solitário e que demanda do pesquisador um esforço intelectual. Por outro lado, a partilha e a socialização possibilitam o fortalecimento de suas construções, estabelecendo parcerias que são tecidas e se solidificam tanto entre os pesquisadores, quanto no amadurecimento individual, podendo se ampliar às estratégias de participação entre grupos de pesquisa e instituições.

A interação entre pesquisadores de instituições distintas têm sido um fator de peso na avaliação dos programas de pós-graduação em educação, inclusive, destacamos a criação de um item no quesito avaliação que confere notoriedade à interinstitucionalidade e à participação em redes de pesquisas. Isso evidencia a relevância e o impacto que as redes de pesquisa possuem para o órgão que coordena a pós-graduação stricto sensu no país. Leite e outros (2014) entendem que as parcerias possibilitam aumentar, também, as métricas de avaliação, pois estimulam maior produção de pesquisas e, consequentemente, mais artigos, o que resulta em maior peso nas produções dos docentes. 
Por sua vez, a pesquisa colaborativa em rede é diferente e tem conceito diverso daquele que utiliza o termo pesquisa colaborativa como uma aplicação colaborativa na pesquisa-ação. Neste artigo, não nos referimos à pesquisa colaborativa, detivemo-nos à colaboração entre pesquisadores, grupos de pesquisa e instituições de ensino superior que, diante de um objetivo e tema comum, decidem por tecer uma rede para o desenvolvimento de suas ações e pesquisas. Notadamente, o foco é a colaboração entre pesquisadores, realizada por meio de redes de pesquisas interinstitucionais, tal como explica Magalhães (2021, p. 7):

[...] o grupo de pesquisadores que se associam em rede, contam com pesquisadores que vêm com maior bagagem formativa, o que não assusta, mas torna-se ajuda necessária para os membros formalizando o como passam a pensarem sobre bases teóricas e metodológicas, em função da própria experiência dos pesquisadores. Esses, geralmente, ocupam-se de ensinar e refletir coletivamente sobre as questões teóricas e metodológicas que o grupo desenvolve. Postura que é reforçada pelo pensamento de Boaventura Santos, que afirma que, no empenho da pesquisa, é necessário ter uma atitude ou presença de uma atitude de errância epistemológica. Essa ideia de manter a atitude de errância epistemológica tem a ver com a capacidade reflexiva do pesquisador, e ela amplia-se na interlocução do trabalho coletivo, o que ajuda a pensar sobre as várias maneiras de pensar e analisar o mesmo caminho de pesquisa. Souza Santos orienta que o pesquisador deve pensar sobre a pluralidade epistemológica existente no campo da pesquisa acadêmica, pois existem olhares de natureza variada para compreender os fenômenos educativos, mas somente na interlocução com grupo da pesquisa em rede se debatem questões relacionadas ao cientificismo estreito, suas linhas de visão unicistas, o que cria uma cegueira epistemológica que precisa ser superada. (MAGALHÃES, 2021, p. 7).

Nesse sentido, a autora ainda ressalta que, nas pesquisas desenvolvidas, há uma tendência, sobretudo das financiadas com temas de abrangência social, de acabarem se rendendo aos preceitos dos Organismos Internacionais ou mesmo às políticas educacionais vigentes, e que nem 
sempre são aquelas que são as mais adequadas para a educação. Dessa forma, Magalhães (2021, p. 7) entende ser necessário se questionar:

[...] nossa postura de pesquisa está atendendo a qual fonte? Qual demanda? Essa é uma constante preocupação do grupo que trabalha em rede: qual demanda será atendida? Ela representa participações sociais? Dará voz a agentes sociais, aos movimentos sociais, ou apenas atende a certas clientelas ou certas ideologias, independentemente do impacto, ou possibilidade de utilização para transformação social?

Tais questionamentos nos fazem refletir sobre a relevância da constituição de rede para uma definição até mesmo ideológica. Nesse sentido, Magalhães (2021, p. 10) ainda defende que a existência da rede

[...] nos ajuda a analisar o fato de que às vezes as questões de fundo são ideológicas, e, embora pareçam importantes socialmente, no fundo tratam de modismos e deliberações de grupos hegemônicos eventuais. Esse não é um processo fácil, exige discussões acirradas e coletivas para que se saia do superficial e opte por uma produção que se relacione e responda às demandas sociais. A pesquisa colaborativa em rede, por manter um eixo de estudo e investigativo que busca aprofundamento nos condicionantes do objeto de estudo para compreendê-lo em sua totalidade, além de posicionamento político e ideológico contra hegemônico, busca evitar a paixão e a ideologia. Isso faz com os estudos e as pesquisas progridam no seu sentido crítico e orgânico, evitando a expressão de desejos internos e os entraves do mercantilismo atual. (MAGALHÃES, 2021, p. 10).

Temos a compreensão de que o desenvolvimento de pesquisas de qualidade depende de fomento, seja de bolsa no âmbito das pesquisas de mestrado e doutorado, seja de outras modalidades de bolsas que são pleiteadas por edital, mas que oferecem suporte para financiamento das pesquisas. Com a redução do investimento por parte das instâncias públicas e a redução das bolsas e do número de editais que abarquem as ciências humanas, observa-se um quantitativo também reduzido de grupos de pesquisas que possuem algum tipo de financiamento das pesquisas a eles vinculados. 
Dessa forma, entendemos que o financiamento existente em um grupo de pesquisa impacta seus resultados, uma vez que, aquele que está vinculado a uma rede de pesquisa pode repartir com as demais, a fim de fortalecê-la. Assim, verificamos que a redução de fomento aos grupos de pesquisa impactam diretamente o desenvolvimento de pesquisas colaborativas em rede, visto que as demandas orçamentárias dessa área poderão não ter condições de serem alcançadas, levando toda a rede a partir para o voluntariado, reduzir drasticamente suas ações ou, ainda, redefinir seus objetivos a partir das possibilidades orçamentárias, para se manter vinculado. Logo, torna-se relevante refletir sobre essas questões que, embora não estejam como objetivo do presente artigo, são latentes quando se observa as razões de existir de uma rede de pesquisa para tratar, diretamente, sobre a formação de professores e o trabalho docente.

Assim sendo, acreditamos ser importante ressaltar que as redes de pesquisa, no geral, e em específico as em educação, investem esforços para o alcance de melhores resultados:

A rede, como um todo, deve ter um projeto executável com desempenho garantido, o qual deve ser usado como âncora. É o que atende ao princípio da continentalidade, isto é, o conjunto de participantes da rede executará uma tarefa comum. Os recursos computacionais que aceleram o acesso e o arquivamento de informação são o cerne da nova mídia e podem ser usados nas tarefas comuns do programa. mas se o projeto é amplo, como normalmente é, deve ser dividido em fase ou subprojeto de um projeto guarda-chuva. Neste nível é que é o princípio da especificidade de constitui. Ele é revelado pela execução de tarefa única de uma unidade participante, mas que contribui para o todo. (MOROSINI e FRANCO, 2001, p. 36).

\section{Redes Colaborativas e sua gênese}

Transformações na sociedade impulsionam pessoas e organizações a buscarem novas formas de conviver, trabalhar e compartilhar dados, informações e conhecimentos. As universidades e seus laboratórios, grupos/núcleos de pesquisa, enquanto centro de produção de conhecimentos científicos, possuem 
papel de destaque no compartilhamento de conhecimentos com a sociedade. É nesse contexto que as redes de pesquisas começam a ser formadas.

Gatti (2005) esclarece que, diante de apontamentos originários da reunião da Associação Nacional de Pós-Graduação e Pesquisa em Educação (ANPEd), de 1978, a rede de intercâmbio entre pesquisadores e pesquisas começou a ser pensada no Brasil a partir da constituição de um Programa Integrado de Educação, fomentado pelo Conselho Nacional de Desenvolvimento Científico e Tecnológico (CNPq), pela Financiadora de Estudos e Projetos (FINEP), pelo Instituto Nacional de Estudos e Pesquisas Educacionais Anísio Teixeira (INEP) e pela Coordenação de Aperfeiçoamento de Pessoal de Nível Superior (CAPES), no período de 1981 a 1992. Tal programa se iniciou com projeto piloto e reuniões sucessivas de avaliação, buscando a aglutinação das ações das quatro agências de fomento. Ao fim do Projeto, a ANPEd teceu um documento que avaliava os resultados do Programa, como também sugeria encaminhamentos.

A autora ainda esclarece que, após as etapas do Programa, ele se vinculou aos grupos de trabalho da ANPEd, aperfeiçoou organizações de trabalho, alargou o alcance de mais envolvidos e se destacou por seu impacto e amadurecimento ao longo dos estágios do Programa. Nesse sentido, ela destaca que:

A autonomia assumida por diversos grupos de trabalho da ANPEd na organização de seus estágios e a organização dos workshops dos últimos anos revela um novo patamar para a área, quer quanto à sua autonomia de trabalho, quer quanto ao aprofundamento de questões relevantes e específicas a cada temática e a metodologias. O próprio desenvolvimento e consolidação de alguns GTs da ANPEd estão associados a esse programa, que propiciou encontros, seminários, estágios, com financiamento garantido para participação dos pesquisadores, formando grupos e algumas redes de referência em várias das subáreas da pesquisa no campo da educação. (GATTI, 2005, p. 132).

A experiência vivenciada nesse projeto, de certa forma, impactou o intercâmbio entre instituições para a consolidação de redes colaborativas de pesquisas, que passou a ser um termo que pode trazer consigo uma 
razão de ser que está subjacente à sua estrutura, ou seja, rede passou a ultrapassar as profissões pesqueiras.

Por volta dos anos de 1960, com a criação das redes telefônicas e, em seguida, com a criação dos microcomputadores e a necessidade de compartilhar a informação entre eles. Com a ampliação do uso dos computadores, ampliou-se também a necessidade de interligação para o compartilhamento de informações, visando a partilha de periféricos como impressoras, e para armazenamento de conjunto de dados, com a finalidade de serem consultados por muitos e em acesso simultâneo. Dessa forma, as redes de computadores nacionais se ampliaram com a interface entre as próprias empresas, com tipos de redes diferenciadas, sempre buscando o atendimento da necessidade. (MARQUES, KIRNER, 1988, p. 3). Mas, por qual razão abordaríamos esse destaque da rede de computadores, já que estamos tratando de rede colaborativa de pesquisa? A justificativa se dá exatamente por entendermos que o uso contínuo desse termo, no sentido das tecnologias, impulsionou a aplicação em outros contextos, que entendemos também ter sido motivador para que "rede" passasse a ser utilizado no âmbito de pesquisas.

Já o termo colaborativo tem sido utilizado em pesquisas que possuem características que se assemelham, em alguns aspectos, à pesquisa-ação. $\mathrm{O}$ termo pesquisa está intrínseco à atividade docente, abrange todas as suas ações, faz parte do ethos docente, de sua constituição e de seu fazer, que é essencialmente investigativo, uma vez que "[...] não há ensino sem pesquisa e pesquisa sem ensino”. (FREIRE, 2006, p. 29).

Ao buscarmos a definição de redes de pesquisa, encontramos o glossário que consta no Diretório dos Grupos de Pesquisa do CNPq, que as caracterizam como aquelas que buscam:

[...] impulsionar a criação do conhecimento e o processo de inovação resultantes do intercâmbio de informações e, sobretudo, da junção de competências de grupos que unem esforços na busca de metas comuns, podendo ou não haver compartilhamento de instalações. (BRASIL, 2020, p. 1). 
No mesmo documento, há um alerta para a especificidade do termo e sua aplicação, sendo diverso de redes sociais de pesquisa:

Não confundir com redes sociais de pesquisa que não são o alvo do Diretório dos Grupos de Pesquisa. Estas visam suprir a necessidade de um ambiente próprio e especializado em uma determinada área do conhecimento, com possibilidades de discussões, networking, compras de insumos, divulgação e comercialização dos resultados de pesquisas e inovações. (BRASIL, 2020, p. 1).

No estudo de Leite et al (2014), os autores se apoiam na definição de Christakis (2010, p. 8), de que "uma comunidade de rede pode ser definida como um grupo de pessoas que estão mais conectadas entre si do que estão em relação a outros grupos de pessoas". Leite e outros (2014) analisam as redes de colaboração em pesquisa na tentativa de elaborar marcadores que possibilitem identificar tanto as motivações quanto as formas de avaliação das redes de pesquisa colaborativa. Tais marcadores indicam o processo de atuação, suas relações e interações no seio dos grupos de pesquisa.

Como forma de compreender a amplitude das redes de pesquisa colaborativa voltadas para estudos sobre formação de professores e trabalho docente, realizamos a busca por algum documento sobre o assunto no sítio eletrônico do CNPq, da Capes e do MEC e em nenhum deles localizamos, até o momento de elaboração do presente artigo, alguma normativa que tivesse critérios pontuais de uma rede de pesquisa. A definição mais completa foi localizada no sítio eletrônico de duas fundações de amparo à pesquisa: de Goiás (FAPEG) e de Minas Gerais (FAPEMIG). A FAPEG regulamenta e define as redes de pesquisa em sua Resolução Normativa Consup/FAPEG n. 6/2007:

Art. $1^{0}$ - Entende-se por Rede de Pesquisa um grupo de entidades por intermédio de seus pesquisadores e profissionais, em permanente interação, organizados para desenvolver conjuntamente projetos de pesquisa científica ou tecnológica que possam contribuir significativamente para $o$ avanço e difusão do conhecimento. 
Art. $2^{\circ}$ - Caracteriza-se como Rede a união de no mínimo 3 (três) ou mais instituições sediadas em Goiás, sendo pelo menos uma de educação superior, ou de pesquisa, com o objetivo de, em conjunto, viabilizar a execução de projetos de pesquisa e/ou desenvolvimento e contribuir significativamente para o desenvolvimento científico e tecnológico do Estado de Goiás. (GOIÁS, 2007, p. 1).

Nessa mesma normativa, encontramos mais elementos com especificações para atuação em Rede, quais sejam: proposição de atividade científica de relevância para o estado; composição de, no mínimo, 3 instituições e que, destas, uma seja de ensino superior, ou instituição de pesquisa sediada no estado; existência de termo de cooperação entre todas as instituições para partilha das produções e recursos materiais; coordenador geral credenciado à Fapeg; integrantes que participem de projetos de pesquisa; demonstração de capacidade da rede, tal como relação qualificada dos envolvidos e da infraestrutura disponível para a Rede. (GOIÁS, 2007).

A composição de um grupo de pesquisa é feita por diversos investigadores, enquanto uma rede pode ter diferentes grupos de pesquisas, o que amplia seu potencial de abrangência e pode alcançar contextos locais, regionais e internacionais. Nesse sentido, uma rede se estabelece quando um grupo de pessoas, instituições, agências e empresas estão em contato e tal interação pode ser representada graficamente. Uma rede de pesquisa e colaboração carrega os mesmos atributos definidores e acrescenta a eles a intenção de produzir conhecimento. Além disso, tal como Maria Isabel da Cunha destaca, em entrevista à Magalhães (2021, p. 8, prelo):

Uma Rede tece uma cultura própria que amalgama experiências anteriores dos participantes e as condições das instituições que albergam a experiência. Cabe bem as sábias palavras do poeta espanhol Machado “[...] Caminhante não há caminho [...] o caminho se faz ao caminhar [...]. Mas cada situação vai exigir uma leitura das condições objetivas que envolvem os interesses, os participantes, as possibilidades, as metas, a resiliência. São essas condições que balizam os processos, os avanços, os ganhos. Mas são elas, também, que ajudam a evitar as dificuldades e minorar o fracasso. 
E assim, ao pensarmos a gênese e constituição das redes de pesquisas, trilhamos espaços e tempos entretecendo referências e seguindo os caminhos já percorridos por pesquisadores mais experientes e o trabalho realizado no interior das entidades e associações de pesquisas.

\section{Percurso Metodológico}

Para alcançar o objetivo de conceituar as redes de pesquisa, suas formas de atuação e elencar quais têm conduzido seus estudos e pesquisas à formação de professores e trabalho docente, optamos por lançar mão da pesquisa bibliográfica, na busca de reunir elementos que servissem de base para a construção da investigação proposta.

Após a escolha da temática "redes de pesquisa e suas formas de atuação", limitamo-nos a elencar quais têm direcionado seus estudos e pesquisas à formação de professores e trabalho docente, como modo de aprofundar no assunto. Dessa forma, traçamos um histórico sobre a criação, a conceituação e a atuação das redes de pesquisas no campo da formação de professores e do trabalho docente no Brasil.

Inicialmente, pesquisamos os descritores Pesquisa - Rede no Portal de Periódicos CAPES/MEC, encontrando 29 (vinte e nove) resultados. Entretanto, ao realizar a leitura dos resumos, constatamos que nenhum dos artigos tratava da temática redes de pesquisa, referindo-se, basicamente, à metodologia de pesquisa-ação (pesquisa colaborativa).

A fim de proceder com uma busca mais refinada, partimos para as páginas das entidades científicas e associações de pesquisa, à procura de obter dados mais robustos quanto à formação das redes de pesquisa. Consultamos os sítios eletrônicos da Anped, da Anfope, da Capes e do Cnpq, e nestes encontramos indicações das redes de pesquisa existentes voltadas para a tratativa da temática de formação de professores e trabalho docente, das quais elegemos as seguintes: 
Quadro 1 - Redes de pesquisa voltadas para temática de formação de professores e trabalho docente no Brasil

\begin{tabular}{|c|c|c|c|}
\hline Rede & $\begin{array}{c}\text { Fundada } \\
\text { em }\end{array}$ & Grupos Integrantes & Endereço \\
\hline $\begin{array}{c}\text { Rede } \\
\text { Universitas/Br }\end{array}$ & 1990 & $\begin{array}{l}\text { GTPS/UFRRJ } \\
\text { GEPPES-UCDB } \\
\text { GEPES - UFPA } \\
\text { GEPES - UNICAMP } \\
\text { GEU - UFRGS } \\
\text { NEDESC-UFG } \\
\text { NEGRA - Núcleo de Estudos sobre } \\
\text { Educação, Gênero, Raça e Alteridade } \\
\text { PRÁXIS - UFRO } \\
\text { PROEDES - UFRJ } \\
\text { Rede de Pesquisadores sobre Associativismo } \\
\text { e Sindicalismo dos Trabalhadores em } \\
\text { Educação Universitátis }\end{array}$ & $\begin{array}{l}\text { http://www.redeunive } \\
\text { rsitas.com.br/p/rede- } \\
\text { universitas_22.html }\end{array}$ \\
\hline $\begin{array}{c}\text { RedEstrado - } \\
\text { Rede Latino- } \\
\text { Americana de } \\
\text { Estudos sobre } \\
\text { Trabalho } \\
\text { Docente }\end{array}$ & 1999 & $\begin{array}{l}\text { Agrega pesquisadores e instituições } \\
\text { interessados no debate político e acadêmico } \\
\text { em Estudos sobre Trabalho Docente, no } \\
\text { contexto da região da América Latina. }\end{array}$ & $\begin{array}{l}\text { https://redeestrado.or } \\
\text { g/apresentacao/ }\end{array}$ \\
\hline $\begin{array}{l}\text { REDECENTR } \\
\text { O Rede de } \\
\text { Pesquisadores } \\
\text { sobre } \\
\text { professores do } \\
\text { Centro-Oeste }\end{array}$ & 2004 & $\begin{array}{l}\text { Programas de pós-graduação em educação } \\
\text { da Região Centro-Oeste - Universidade de } \\
\text { Brasília (UnB), } \\
\text { Universidade Federal de Mato Grosso UFMT), } \\
\text { Universidade Federal de Mato Grosso do Sul } \\
\text { (UFMS), } \\
\text { Universidade Federal de Goiás (UFG) } \\
\text { Universidade Federal de Uberlândia (UFU) } \\
\text { Universidade Federal de Catalão (UFCAT) } \\
\text { Universidade de Uberaba (UNIUBE) }\end{array}$ & 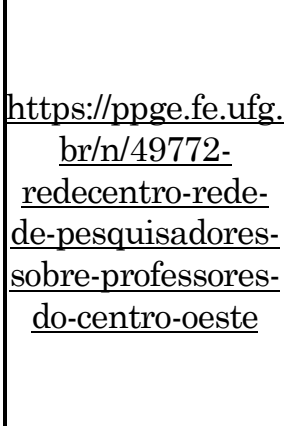 \\
\hline \begin{tabular}{|l} 
Rede ASTE \\
Rede de \\
Pesquisadores e \\
Pesquisadoras \\
sobre \\
Associativismo e \\
Sindicalismo dos \\
Trabalhadores e \\
das \\
Trabalhadoras \\
em Educação
\end{tabular} & 2009 & $\begin{array}{l}\text { Adrián Ascolani (Argentina), } \\
\text { Amarílio Ferreira Jr. (Brasil), } \\
\text { André Robert (França), } \\
\text { Aurora Loyo (México), } \\
\text { Carlos Bauer (Brasil), } \\
\text { Deise Mancebo (Brasil), } \\
\text { Julián Gindin (Brasil), } \\
\text { Márcia Ondina Vieira Ferreira (Brasil), } \\
\text { Marcos Ferraz (Brasil), } \\
\text { Ricardo Pires de Paula (Brasil), } \\
\text { Rosa Serradas (Portugal), } \\
\text { Sadi dal Rosso (Brasil) } \\
\text { Savana Diniz Gomes Melo (Brasil). }\end{array}$ & $\begin{array}{l}\text { https://redeaste.iric } \\
\text { e-conicet.gov.ar/ }\end{array}$ \\
\hline
\end{tabular}




\begin{tabular}{|c|c|c|c|}
\hline $\begin{array}{c}\text { Rede } \\
\text { Internacional } \\
\text { de Educação On } \\
\text { life - } \\
\text { RIEOnLife }\end{array}$ & 2020 & $\begin{array}{l}\text { Unisinos; } \\
\text { GPe-dU - Grupo de Pesquisa Digital Unisinos; } \\
\text { UniLaSalle; } \\
\text { GP-Cotedic; } \\
\text { Universidade Estadual do Maranhão; } \\
\text { Universidade Aberta de Portugal; } \\
\text { Instituto Federal do Norte de Minas Gerais; } \\
\text { Faculdade CMB; } \\
\text { Universidade Federal de Pernambuco; } \\
\text { Grupo Marista; } \\
\text { Fundação Universidade Federal de Rondônia; } \\
\text { Centro Universitário Vale do Salgado; } \\
\text { Universidade Franciscana; } \\
\text { Universidade Federal de Sergipe; } \\
\text { Universidade Feevale; } \\
\text { Universidade Estadual do Oeste do Paraná. }\end{array}$ & https://rieonlife.com/ \\
\hline
\end{tabular}

Fonte: Elaborado pelas autoras a partir de dados coletados no sítio eletrônico das redes de pesquisa

A Rede Universitas/Br se estruturou a partir de projetos acadêmicos de pesquisa integrados, o que tem resultado em seminários, publicações coletivas, formação de grupos, núcleos e diretórios de pesquisa, constituição de linhas de pesquisa em programas de pós-graduação e formação de estudantes no âmbito da iniciação científica e dos cursos de mestrado, doutorado e pós-doutorado, diretamente ligados aos pesquisadores da Rede. A entrada de pesquisadores e estudantes na Rede tem ocorrido por meio de projetos de pesquisa integrados e articulados. A indicação cabe aos coordenadores dos projetos de pesquisa e pesquisadores da Rede, e cada projeto integrado ou articulado deve garantir autonomia e fidelidade aos princípios históricos e críticos que a norteiam. Segundo a própria Rede Universitas (2021), eles buscam a pesquisa e a "[...] interlocução entre pares que têm em comum a área do conhecimento Políticas de Educação Superior”.

Uma das últimas ações da Rede Universitas culminou na produção de um e-book, publicado em 2021, denominado Política de Educação Superior: educação profissional tecnológica e do campo (MANCEBO et al, 2021), que se originou de uma ação coletiva para a produção de artigos daqueles que integram a Rede Universitas. Essa publicação é fruto de trabalhos submetidos ao Seminário Online, em maio de 2021, que foi coordenado pela Faculdade de Educação da Universidade Federal de Goiás com participação 
do Programa de Pós-Graduação em Educação da Universidade Estadual de Goiás e da Pontifícia Universidade Católica de Goiás. O evento supracitado se caracterizou como uma ação da Rede Universitas, com vistas ao compartilhamento de pesquisas sobre políticas de educação superior, tais como educação do campo, formação de professores e suas contribuições para as políticas de educação superior e para o desenvolvimento do campo e da sociedade brasileira, e novos modos de regulação, tendências em construção e trabalho docente na educação profissional tecnológica.

Já a RedEstrado, Rede Latino-Americana de Estudos sobre Trabalho Docente, tem como objetivo geral "contribuir para a disseminação do conhecimento sobre o trabalho docente na América Latina e, consequentemente, para a construção de políticas públicas mais assertivas” (REDESTRADO, 2021, p. 1).

É uma importante produtora e difusora de conhecimento sobre o trabalho docente na região latino-americana, articulando pesquisadores vinculados a universidades e centros de pesquisa, aos sindicatos e a outros movimentos que atuam em favor da valorização da profissão docente. Está estruturada em doze países latino-americanos: Argentina, Brasil, Chile, Colômbia, Costa Rica, Cuba, Equador, México, Paraguai, Peru, Porto Rico e Uruguai.

A RedEstrado desenvolve pesquisas e estudos comparados, além de realizar seminários nacionais, debates sobre temas específicos, publicações de livros e outros materiais, como anais de seminários. Busca a promoção bienal de seminários internacionais em diferentes países da América Latina, os quais já foram realizados: no Rio de Janeiro/Brasil (1999; 2006), Belo Horizonte/Brasil (2002), Salvador/Brasil (2014), Guadalajara/México (2001), Buenos Aires/Argentina (2003; 2005; 2008); Santiago/Chile (2012); Lima/Peru (2010; 2018). Observa-se que os Seminários não se centralizam em um único país, mas busca diversificar o local de realização nos países da América Latina, a fim de debater sobre a condição docente no contexto latinoamericano. Como a rede não conta com fonte de financiamento, as atividades formativas são realizadas com os apoios das universidades às quais seus membros estão vinculados (REDESTRADO, 2021). 
Uma das ações da RedEstrado foi a publicação de um livro, em 2015, intitulado Inclusão democrática e direito à educação: desafios para a docência na América Latina, organizado por Dalila Andrade Oliveira, Myriam Feldfeber e Elizeu Clementino de Souza, com enfoque no debate sobre a docência em contexto de educação inclusiva e democrática (OLIVEIRA, FELDFEBER, SOUZA, 2015), obra elaborada em parceria com a rede internacional intitulada INR/WERA (International Research Network of World Education Research Association).

Outra rede identificada é a Redecentro - Rede de Pesquisadores sobre professores do Centro-Oeste, que tem como objetivo geral "analisar a produção sobre o professor, explicitar os vários enfoques epistemológicos do ponto de vista de sua conexão interna e de sua relação com os fatores" (REDECENTRO, 2021, p. 1) e nasceu em meados de 2000, sendo institucionalizada em 2004. Esta tem um caráter marcadamente cooperativo, que busca agregar pesquisadores de várias disciplinas e de vários contextos da Região CentroOeste, num esforço de superar a fragmentação da produção dos trabalhos em educação, portanto, seu projeto reúne professores-pesquisadores e estudantes numa perspectiva interdisciplinar (REDECENTRO, 2021).

Em entrevista à Tiago Zanquêta de Souza, a coordenadora geral da RECECENTRO, Solange Martins Oliveira Magalhães (2021, p. 8), esclarecenos como tem sido a condução dos trabalhos desenvolvidos por eles:

[...] dialogamos e valorizamos sobre a contribuição de outros pesquisadores, eles se somam na superação de uma produção que se norteia na justaposição de autores. Ao contrário, debatem-se seus elos, suas interconexões e, mesmo que sejam autores de perspectivas diferentes, sempre se mostram como contribuições ou contraposições na composição de novas críticas e limites do pensamento construído coletivamente. Eles são sempre cabíveis de serem colocados e debatidos, na direção de uma construção coletiva, que também sustentará a autoral no campo da pesquisa educacional.

Um exemplo de ação da REDECENTRO foi a publicação de uma obra organizada por Souza, Magalhães e Queiroz (2017), que aborda estudos acerca das pesquisas acadêmicas sobre a formação de professores no âmbito das 
Universidades integrantes à época, da REDECENTRO: UFG, UNB, UFU, UFMS, UFMT, UFT, Uniube. A obra foi marcante para a Rede por trazer traços da interinstitucionalidade, demonstrando a articulação de objetivos, princípios e metodologia comum entre os pesquisadores e seus respectivos grupos, corroborando para uma produção uníssona.

A Rede Aste - Rede de Pesquisadores e Pesquisadoras sobre Associativismo e Sindicalismo dos Trabalhadores e das Trabalhadoras em Educação - foi outra identificada neste estudo, a qual foi aprovada e constituída na plenária final do I Seminário sobre Associativismo e Sindicalismo Docente, realizado em 2009, no Rio de Janeiro. Trata-se de uma Rede que tem se internacionalizado, ampliando o diálogo entre pesquisadores de diferentes países. Os resultados do trabalho promovido no âmbito da Rede foram, entre outros, a ampliação da discussão sobre os referenciais teórico-metodológicos que sustentam as pesquisas na área; o incentivo à produção e à socialização de pesquisas sobre o tema em vários países; e, ainda, a perspectiva de publicações coletivas das produções de seus integrantes. Destaca-se também a reafirmação da importância de vigência de relações solidárias, abertas e horizontais na Rede (ASTE, 2021).

A Rede Aste se coloca como um espaço aberto a pesquisadores, centros e núcleos de pesquisas, sindicalistas, trabalhadores da educação e estudantes que buscam divulgar e debater suas produções sobre associativismo e sindicalismo na educação. Ao visitar sua página na internet, pudemos ter acesso a vários trabalhos produzidos na rede, dentre os quais apontamos dois que tratam diretamente do nosso tema de interesse: formação de professores e trabalho docente. No artigo "Alguns Aspectos da Reorganização do Movimento dos Professores Públicos do Estado do Rio de Janeiro (1977-1980)", de Henrique Garcia Sobreira (2001), que é fruto de sua dissertação de mestrado, o autor trata do movimento dos professores públicos conduzido pelo Centro Estadual de Profissionais de Ensino do Rio de Janeiro, entre 1977 e 1980. É importante, resgatar a história da Entidade por meio de seus registros e documentos e investigar a possibilidade de as organizações docentes se 
configurarem como "educadoras do educador", inaugurando uma nova etapa na profissionalização do magistério. Do confronto entre os documentos de partidos políticos (analisando o movimento) e as entrevistas com diversos participantes do movimento, foi reconstruída a história dos primeiros anos da entidade. Dessa forma, o papel do sindicato como Aparelho de Hegemonia (no sentido gramsciano, organizador político para além de defensor dos interesses econômico-corporativos) é posto em dúvida diante dos resultados atingidos (ASTE, 2021).

Em um dos temas apresentados no Seminário Associativismo e Sindicalismo organizado pela Rede, "A natureza sócio-histórica do trabalho docente: do sacerdócio à sindicalização", Miranda (2009, p. 7), discute:

O professor não planeja e executa o seu trabalho sob total liberdade. Há limites para tal. Portanto, cabe discutir quais são as condições de planejamento e execução das propostas pedagógicas. A questão que se coloca é: qual seria o limite desta liberdade? Então caímos em situação similar àquela que Marx se refere sobre a dupla liberdade do trabalhador de vender a sua força de trabalho e ser livre da propriedade dos meios e instrumentos de produção. Poderíamos fazer uma analogia dizendo que o professor possui uma dupla autonomia, que se expressa por um lado, pela autonomia de exercer sua criatividade sem tempo para o planejamento dada a intensificação de sua jornada (chegando a trabalhar até três turnos por dia em escolas diferentes) e, por outro lado, a autonomia de planejar aulas com a sua baixa qualificação de fato - ainda que a escolaridade formal esteja em ascensão. Outro aspecto que podemos destacar nesta direção é o das avaliações externas à sala de aula, à escola, à rede de ensino. (MIRANDA, 2009, p. 7).

A Rede Internacional de Educação On life (RIEOnLife), que tem como objetivo "co-criar uma rede/plataforma de Educação OnLIFE, conectando pesquisadores, gestores, professores e estudantes para, a partir do conhecimento das diversas realidades educacionais brasileiras e internacionais", foi outra por nós identificada. Conforme informações eletrônicas, ela foi organizada pelo Grupo de Pesquisa Educação Digital GPe-dU - UNISINOS/CNPq, em parceria com a Universidade Aberta de Portugal - UAb-PT, e vinculada ao projeto de pesquisa Transformação Digital na Educação, sendo financiada pelo CNPq. 
Compõe-se de mestres, doutores e pós-doutores, egressos do GPe-dU e que atuam em diferentes instituições/regiões do Brasil e no exterior. Essa rede surgiu pela necessidade de ouvir, discutir e refletir com gestores, professores e estudantes, de diferentes níveis e contextos nacionais e internacionais, sobre as compreensões, as ações e as proposições relacionadas à educação na contemporaneidade, a fim de potencializar-se enquanto rede que pensa e constrói uma Educação OnLIFE (RIEOnLIFE, 2021).

Ao visualizar os objetivos que cada rede colaborativa propõe, percebe-se haver algo em comum entre as cinco redes aqui mencionadas, qual seja, difundir conhecimento acerca do trabalho docente e da formação de professores, o que corrobora com a conceituação disposta no glossário do Diretório dos Grupos de Pesquisa do CNPq (2020. p. 1): "redes de pesquisa visam impulsionar a criação do conhecimento e o processo de inovação resultantes do intercâmbio de informações". Ao mesmo tempo, percebe-se que, mesmo tendo uma ação em comum, cada uma percorre caminhos diferenciados.

Convém ressaltar que as experiências de que tratam as redes de pesquisas colaborativas aqui trazidas corroboram com Gallo (s.d.) por proporem que a articulação do conhecimento não fique dependente de processos discursivos acadêmicos/científicos.

Outro destaque percebido é que, embora as redes de pesquisas colaborativas estejam em expansão, ainda há uma escassez de estudos que se proponham a explicar e descrever o propósito e como se dá a atuação.

\section{Considerações Finais}

Ao finalizarmos este artigo, não poderíamos deixar de problematizar algumas questões em torno da criação, da formação e da aderência do trabalho colaborativo em redes de pesquisa. Do ponto de vista crítico analítico, evidenciamos a existência de processos em confronto e, ao mesmo tempo, complementaridade. O primeiro aspecto é ligado ao acadêmico, materializado nos sítios eletrônicos que descrevem as redes de pesquisa, 
em link com o site da própria instituição universitária onde o grupo está alocado. A ênfase dada a esse aspecto caracterizaria uma rede de cunho mais representativo em termos institucionais.

O segundo aspecto relaciona-se ao científico, e materializa-se nos produtos que a rede vem produzindo (autoria coletiva resultando em teses, dissertações, artigos, livros etc). A ênfase dada a esse aspecto caracterizaria uma rede de natureza mais científica, com mais experiência em pesquisa, ou os nomeados centros de excelência.

O terceiro aspecto identificado diz respeito aos recursos que financiam as pesquisas, e é justamente esse o aspecto que nos chama a atenção, visto que, se por um lado, a colaboração de pesquisadores em rede propicia:

[...] as numerosas iniciativas de colaboração tanto entre pesquisadores individuais quanto com grupos de pesquisa [e] tem servido a vários objetivos, como, por exemplo, para centros mais inexperientes buscarem articulação com centros de excelência, para se ampliar o escopo multidisciplinar das investigações quando a agregação acontece entre pesquisadores de várias áreas, para se estreitar as relações entre ciência e tecnologia buscando maior impacto da pesquisa em setores econômicos ou nas políticas públicas sociais, ou mesmo visando a aumentar o nível de intercâmbio internacional entre centros de pesquisa de diferentes países. (MENDES; TANNÚSVALADÃO; D’AFFONSECA, 2016, p. 5)

Por outro lado, obriga a estruturar-se a partir de uma hierarquia científica, que nem sempre estaria estabelecida por critérios exclusivamente científicos ou acadêmicos, mas por critérios econômicos. Essa perspectiva responde a uma questão crucial, que não está explícita, mas que constitui a razão de ser de muitas das redes de pesquisa, na medida em que se expressaria como uma multifacetagem da crise financeira da universidade brasileira, enquanto entidade de pesquisa, induzindo a necessidade de alinhamento da instituição, por meio das redes, com fontes externas de fomento. Ao nosso ver, isso reverbera nas condições de produção históricas e ideológicas que estão na sustentação da constituição das chamadas redes de pesquisa, influenciando nos critérios que as constituem. 
Sopesar os aspectos levantados acima não seria ético de nossa parte, mas gostaríamos de reiterar nossa convicção da importância do trabalho em rede, embasando-nos nas palavras de Magalhães (2021, p. 9), ao afirmar que:

[...] a pesquisa colaborativa e em rede tem um papel essencial que diz da forma como o campo vai se afirmar no campo científico, seus pesquisadores têm essa responsabilidade. Sabemos que o campo da pesquisa educacional, pelo menos aqui no Brasil, enfrenta a dificuldade de ser reconhecido, os trabalhos não são considerados como científicos, aspecto que pode ser superado quando a produção é coletiva, pois passa pelo crivo ampliado do rigor e da relevância de vários pesquisadores que optaram por fazer esse debate.

Magalhães (2021, p. 9) esclarece, ainda, que a vinculação à rede possibilita ao pesquisador a aquisição de "[...] conhecimento novo, a partir de uma dimensão crítica, do rigor e métodos de trabalho, de explicitação clara de como os dados foram sistematizados"'. A autora entende que esse aspecto é emblemático para o campo da pós-graduação, pois um expressivo quantitativo de pesquisas “[...] não mostram a presença de lógica epistemológica e interpretações com base em teorias sólidas e que dialogam entre si”. (MAGALHÃES, 2012, p. 9).

Por isso a nossa defesa dos aspectos formativos das redes de pesquisas, da possibilidade de ampliação das produções por meio das publicações, que podem corroborar com o crescimento dos Programas de Pós Graduação e também como forma de se buscar a ampliação das redes de contatos para se buscar a internacionalização dos Programas.

Com base no objetivo geral que delimitamos nesta investigação, verificamos, a título de finalização deste texto, e em termos de características gerais do cenário nacional da interação entre grupos de pesquisa pertencentes às redes, que as redes de pesquisa brasileiras, dentro da amostra selecionada, são os atores que procuram e iniciam as relações de parceria na maioria dos casos. Verificou-se também que a informalidade nas redes é um elemento ainda presente, bem como a baixa adesão às ações desenvolvidas nelas, conforme foi possível ser visto no desdobramento das atividades cooperativas realizadas em redes. 
As atividades desenvolvidas nas ações cooperativas concentram-se entre pesquisa aplicada em produtos e processos e atividades frutos de editais específicos e com financiamento por agências de fomento, em sua maioria, nacionais.

Todavia, observa-se que, diante de todas as dinâmicas empreendidas em prol da consolidação de redes de pesquisa mais robustas, há um esforço mútuo de manutenção dos grupos de pesquisa e, deles, tem-se buscado não nos afastar, visto que o presente está posto e, nesses grupos, para juntos se constituírem rede, precisam se mobilizar para suavizar as circunstâncias. Seguindo Carlos Drummond de Andrade (1977, p. 55), vamos fazer rede, "vamos de mãos dadas".

\section{Referências}

ANDRADE, Carlos Drummond de. Reunião. Dez livros de poesia. 8.ed. Rio de Janeiro: José Olympio, 1977. (Sentimento do Mundo.)

ASTE, Rede de Pesquisadores e Pesquisadoras sobre Associativismo e Sindicalismo dos Trabalhadores e Trabalhadoras em Educação. 2021. Disponível em: https://redeaste.irice-conicet.gov.ar/. Acesso em: 10 jul. 2021. CENTRO. Rede, 2021. https://ppge.fe.ufg.br/n/49772. Disponível em: https://ppge.fe.ufg.br/n/49772-redecentro-rede-de. Acesso em: 30 jun. 2021.

CUNHA, Maria Isabel da. Diálogos sobre a Pesquisa Colaborativa e em Rede: "o desafio de construir uma caminhada coletiva". [Entrevista cedida a] Solange Martins Oliveira Magalhães. Revista Ensino em Revista, no prelo, 2021.

ESTRADO. Rede, 2021. https://redeestrado.org/. Disponível em: https://redeestrado.org/apresentacao/. Acesso em: 30 jun. 2021.

FREIRE, P. Pedagogia do Oprimido. 16. ed. Rio de Janeiro: Paz e Terra, 2006.

GALLO, Solange L. Redes de pesquisa e a produção de conhecimento científico. (s.d.). Disponível em: http://dlm.fflch.usp.br/sites/dlm.fflch.usp.br/files/Solange\%20Gallo.pdf. Acesso: 09 jul. 2021.

GATTI, Bernadete A. Formação de grupos e redes de intercâmbio em pesquisa educacional: dialogia e qualidade. Revista Brasileira de Educação. Set /Out /Nov/Dez 2005 n 30, p. 124-132. Disponível em:

https://gestaoeducacaoespecial.ufes.br/sites/gestaoeducacaoespecial.ufes.br/files/fiel d/anexo/a10n301.pdf. Acesso: 09 jul. 2021.

LEITE, Denise et. al. Avaliação de Redes de Pesquisa e Colaboração. Avaliação, Campinas; Sorocaba, SP, v. 19, n. 1, p. 291-312 mar. 2014. Disponível em: https://doi.org/10.1590/S1414-40772014000100014. Acesso em: 15 maio 2021. 
MAGALHÃES, Solange Martins Oliveira. Entrevista com a professora e pesquisadora Solange Martins Oliveira Magalhães. [Entrevista cedida a] Tiago Zanquêta de Souza. Revista Profissão Docente, Uberaba-MG, v.21, n.46, p.01-15, 2021. Disponível em: http://dx.doi.org/10.31496/rpd.v21i46.1411. Acesso em: 30 jun. 2021.

MANCEBO, Deise; CARVALHO, Renata Ramos da Silva; FERREIRA, Diana Regina dos Santos Alves; PAZ, Suelaynne Lima (orgs.). Política de educação superior: educação profissional tecnológica e do campo. Anápolis, GO: Editora UEG, 2021.

MARQUES, Eduardo; KIRNER, Cláudio. Redes de computadores de alta velocidade, uma solução nacional. Ciência Hoje, v. 7, n. 41, p. 2-10. abr. 1988.

MENDES, Enicéia Gonçalves; TANNÚS-VALADÃO, Gabriela; D’AFFONSECA, Sabrina Mazo. Impactos e desafios das redes de pesquisa: o caso do observatório nacional de educação especial. Revista Teias, v. 17, n. 46, p. 5-22, out. 2016. Disponível em: https://doi.org/10.12957/teias.2016.25891. Acesso em: 19 jun. 2021.

MIRANDA, Kênia. A Natureza sócio-histórica do Trabalho Docente: do sacerdócio à sindicalização. Associativismo e sindicalismo docente no Brasil. Rio de Janeiro, 17 e 18 de abril de 2009. Seminário para discussão de pesquisas e constituição de rede de pesquisadores.

MOROSINI, Marília Costa; FRANCO, Maria Estela Dal Pai. Gestão de redes de pesquisa em educação superior: questão de princípios e ethos. In: FRANCO, Maria Estrela Dai Pai; MOROSINI, Marília Cota. (orgs.). Redes acadêmicas e produção do conhecimento em educação superior. Brasília: Instituto Nacional de Estudos e Pesquisas Educacionais, 2001. p. 35-50.

OLIVEIRA, Dalila Andrade; FELDFEBER, Myriam; SOUZA, Elizeu Clementino de. Inclusão democrática e direito à educação: desafios para a docência na América Latina. Belo Horizonte: Editora Unika, 2015.

RIEOnLife, Rede Internacional de Educação On life, 2021. Disponível em: https://rieonlife.com/. Acesso em: 30 jun. 2021.

SOBREIRA, Henrique Garcia. Alguns Aspectos da Reorganização do Movimento dos Professores Públicos do Estado do Rio de Janeiro (1977-1980). Educ. Soc. v. 22, n. 77, dez 2001. Disponível: https://doi.org/10.1590/S0101-73302001000400007. Acesso em: 19 jun. 2021.

SOUZA, R. C. C. R.; MAGALHÃES, S. M. O. QUEIROZ, V. R. F. (orgs.). $A$ pesquisa sobre professores(as) no Centro-Oeste dimensões teóricas e metodológicas. Goiânia: IFT-GO, 2017.

UNIVERSITAS. Rede, 2021. https://universitas.com.br/. Disponível em: http://www.redeuniversitas.com.br/p/rede-universitas_22.html. Acesso em: 30 jun. 2021. 